\title{
Ser professor de geografia: divagações, ações e reflexões
}

\section{Be a Geography Teacher: divagations, actions and reflections}

\section{Sea un Profesor de Geografía: divagaciones, acciones y reflexiones}

Maria Isabel Castreghini de Freitas ${ }^{1}$ http://orcid.org/0000-0001-6062-1720

\footnotetext{
${ }^{1}$ Professora Doutora Associada (Livre-Docente) em Cartografia e SIG - Universidade Estadual Paulista - UNESP - Rio Claro SPBrasil, Professora aposentada DEPLAN/IGCE - isabel.freitas@ unesp.br
}

\section{Resumo}

Este artigo pretende compartilhar reflexões de autores que desenvolvem estudos em Geografia, formação docente e qualidade de ensino combinados com divagações e experiências profissionais da autora no que concerne à identidade docente de Geografia, a formação inicial em Geografia, bem como experiências de formação continuada no CECEMCA/UNESP (2004 - 2009). Dentre os desafios colocados ao leitor, diante das discussões apresentadas no texto, ficam o pensar na forma como se vem conduzindo a formação inicial dos professores nas Universidades, sugerindo ações intergradoras de disciplinas, ações pedagógicas de caráter contínuo envolvendo os sistemas de ensino e as Universidades e a proposição da formação continuada de professores pautada na troca de experiências entre os pares e nas necessidades dos docentes e das escolas.

Palavras-chave: Geografia. Identidade docente. Formação continuada.

\begin{abstract}
This article intends to share the reflections of authors who develop studies in Geography, teacher education and quality of education combined with ramblings and professional experiences of the author regarding the Geography teacher identity, the initial formation in Geography, as well as continuing education experiences at CECEMCA/UNESP (2004 - 2009). Among the challenges presented to the reader, in the light of the discussions presented in the text, are thinking about the way in which the initial formation of teachers in universities has been conducted, suggesting integrating actions of disciplines, continuous pedagogical actions involving educational systems and universities. and the proposition of continuing teacher education based on the exchange of experiences between peers and the needs of teachers and schools.
\end{abstract}

Keywords: Geography. Teaching identity. Continuing education.

\section{Resumen}

Este artículo pretende compartir las reflexiones de los autores que desarrollan estudios en Geografía, educación docente y calidad de la educación combinados con divagaciones y experiencias profesionales del autor con respecto a la identidad del profesor de Geografía, la formación inicial en Geografía, así como experiencias de educación continua en CECEMCA / UNESP (2004 - 2009). Entre los desafíos planteados al lector, a la luz de las discusiones presentadas en el texto, está pensar en la forma en que se ha llevado a cabo la formación inicial de docentes en las universidades, sugiriendo acciones integradas de disciplinas, acciones pedagógicas continuas que involucran sistemas educativos y universidades y la propuesta de formación 
continua del profesorado basada en el intercambio de experiencias entre compañeros y las necesidades de los docentes y de las escuelas.

Palabras clave: Geografía. Identidad docente. Educación continua.

Recebido em: 29/11/2019

Aceito para publicação em: 27/12/2019

"A visão de mundo mais perigosa é a daqueles que não viram o mundo".

(Alexander von Humboldt)

\section{Introdução}

Este artigo resulta de minha trajetória docente e registra as reflexões e ações construídas ao longo dos anos em que atuei formando professores de Geografia e desenvolvendo em ações de formação continuada de professores na UNESP - Campus de Rio Claro, onde trabalhei por 34 anos. Ele é fruto de minha participação na Mesa Redonda Formação e Construção da Identidade Docente Geográfica: Dilemas e Perspectivas na Contemporaneidade, ocorrida em 4 de novembro de 2019, no XX Encontro de Geografia da UESC, Ilhéus - BA.

$\mathrm{O}$ artigo tem como objetivo contribuir com as discussões acerca da identidade docente em Geografia, bem como compartilhar experiências sobre formação inicial e continuada de professores.

O texto pauta-se em diferentes momentos: nas reflexões sobre o que é identidade docente e de como formamos a identidade dos docentes de Geografia; nas ações das Universidades brasileiras na formação inicial e as dificuldades da Educação Básica no Brasil e, finalmente, nas experiências de Formação Continuada de Professores, em especial os de Geografia, tendo como exemplo o Centro de Formação de Professores CECEMCA/UNESP.

O assumir a profissão de professor não nos deixa ilesos. O professor é, basilarmente comprometido com aspectos para além do domínio da matéria que leciona. O professor forma pessoas, abre caminhos para que tais indivíduos se apropriem dos conhecimentos científicos e façam intervenções na sociedade e no ambiente. $\mathrm{O}$ "ser professor" vai além do individual, da construção de uma vida voltada para si mesmo e 
faz aflorar o pensar no coletivo, na comunidade. Muitas vezes ouvimos dizer que "ser professor" é mais missão do que profissão, e concordo em parte com tal afirmação. O ser professor precisa vir de dentro, precisa de uma vontade maior e interior, que se tem ou não se tem, difícil de se aprender em sala de aula. O professor já nasce professor, só precisa tomar consciência disso ao longo da vida. Mais ou menos como afirmava Auguste Rodin quando questionado sobre sua criação artística, sobre como conseguia conceber esculturas tão magníficas de blocos de mármore: "Eu não invento nada. Eu redescubro". Assim também o ser professor, mais do que uma vocação, é uma redescoberta.

\section{O que é identidade docente: quando se dá o "click"?}

Todos tivemos um momento de transição entre o ser aluno, aquele que frequentou a Universidade, realizou atividades previstas nas disciplinas e fora delas, participou de eventos, debateu, questionou, realizou trabalhos de campo e estágios em escolas, provou domínio de conteúdos e práticas e se tornou o professor que conduz a formação de alunos em sala de aula. Que momento é esse, quando se dá o "click" e mudamos de papel? E porque o professor, muitas vezes, não nos sentimos preparados?

Em um estudo sobre a inserção à docência no Ensino Superior as autoras Stivanin; Zanchet (2015) lembram a expressão utilizada na década de 1980 por Simon Veenman para caracterizar esse momento inicial da carreira docente:

Ao pesquisar os professores da escola básica, Veenman (1988) usou a expressão "choque com a realidade", para expressar os conflitos existentes entre as idealizações feitas pelos professores e a realidade que eles encontram no espaço de trabalho quando iniciam a carreira. (STIVANIN; ZANCHET, 2015, p. 70)

Acredito que esse "choque com a realidade" que todo professor tem no inicio da carreira, traz a ele alguma resistência, de maior ou menor grau, para assumir seu novo papel na condução de uma atividade didática. Existem estratégias pessoais e institucionais que podem contribuir para que essa transição se dê de forma fluida e eficaz, conforme pretendo abordar nesse item.

Se considerarmos à etmologia da palavra "identidade", encontramos em Michaelis (2019), dentre as várias definições: série de características próprias de uma pessoa ou coisa por meio das quais podemos distingui-las (MICHAELIS, 2019, s.p.). 
Nesse aspecto que características nos unem e nos tornam parte do "ser professor", e nos transformam num grupo coeso e específico, diferente dos demais?

Em contato com uma reportagem da Revista Carta Capital (RODRIGUES, 2015) com o tema " O que faz o bom professor", datada de 27/07/2015, tive conhecimento de pesquisa da Fundação Sutton Trust em parceria com Universidade de Durham, ambas da Inglaterra, que desenvolveram um estudo sobre quais as combinações de atitude, conhecimento e de ambiente que permitem a formação de grandes educadores.

No estudo, de acordo com Rodrigues (2015), os pesquisadores encontraram 4 aspectos que, juntos, propiciam a constituição de bons professores, que foram por mim organizados (Diagrama 1).

Diagrama 1- O que faz "grandes educadores".

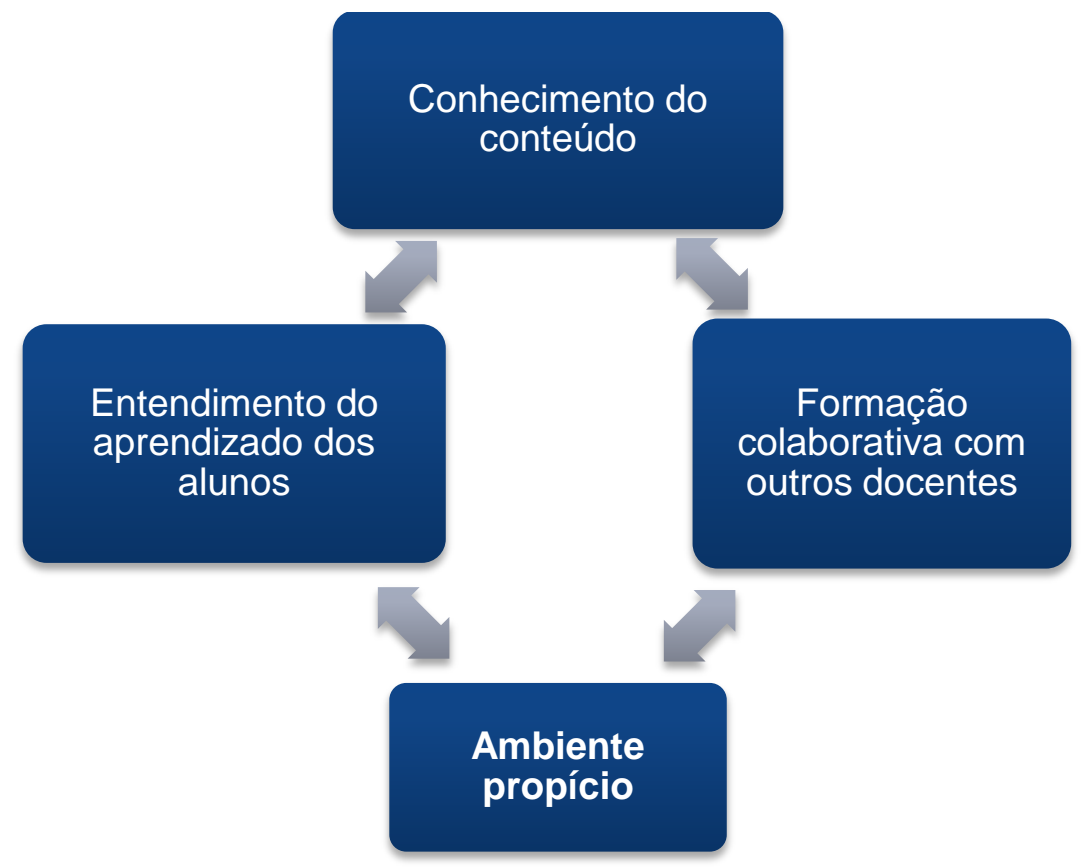

Fonte: Rodrigues (2015) - Organizado por Freitas, M.I.C. (2019)

De acordo com os resultados da pesquisa, com os quais concordo e tomo a liberdade de ampliar com minha própria experiência de formação continuada de professores, a consolidação de um grande educador decorre de quatro caracteristicas principais:

1. Conhecimento do Conteúdo: um educador necessita dominar o conteúdo de sua disciplina, sem o qual não é possível haver o aprendizado por parte dos alunos. Esse aspecto depende diretamente da sua formação inicial e continuada, momentos em que o professor tem condições de consolidar seus 
conhecimentos em aulas expositivas, aulas práticas, leituras e realização de pesquisas individuais e em grupo;

2. Entendimento do aprendizado dos alunos: esta característica está diretamente vinculada à sua introdução às disciplinas pedagógicas, por meio das quais é possível ter acesso aos principais métodos de ensino e de avaliação do desempenho, mas também, e de forma não menos importante, à sensibilidade e compreensão do professor sobre como se dá o aprendizado na faixa etária em que atua.

Conforme os autores do estudo do Centro de Avaliação e Moniotoramento (CEM), da Universidade de Durham e Fundação Sutton Trust, Coe et al. (2014), os professores também devem entender a maneira como os alunos pensam sobre o conteúdo para que possam avaliar o pensamento por trás de métodos não padronizados, por eles adotados, e identificar possíveis conceitos errôneos.

O olhar atento ao aluno, quais são os seus interesses, anseios e necessidades educativas, que passam por uma visão mais ampla de sua formação, envolvendo aspectos comportamentais, de convívio e os diferentes potenciais de cada um. Encontrar os canais de comunicação adequados permite ao professor estimular os alunos à compreensão do conteúdo abordado, o que é fundamental para sua formação escolar;

3. Formação colaborativa com outros docentes: não só as habilidades individuais fazem, de um professor, um bom educador. $\mathrm{O}$ aprendizado conjunto e a troca de experiências com outros professores, além de ampliar seus conhecimentos de forma interdisciplinar, possibilita uma efetiva construção coletiva do saber escolar. A capacidade de dialogar e de identificar outros pontos de vista permitem ao professor seu aprimoramento intelectual e humano;

4. Ambiente propício: o ambiente de trabalho é fundamental para que qualquer profissional se aprimore e evolua. O mesmo se dá com a carreira docente, que ao se desenvolver em ambiente cujas lideranças estimulem o aprimoramento individual e da equipe, bem como dando oportunidade de participação ativa dos que vivem a escola para melhorar as relações interpessoais e as condições de ensino, permite a criação de laços mais 
fortes que os exclusivamente profissionais, de comprometimento com a instituição e com a disseminação do saber.

Com podemos notar, as duas primeiras características possuem forte caráter individual e estão associadas às habilidades consolidadas do professor enquanto as últimas dizem respeito à politica educacional vigente e a forma de gestão adotada em sua Instituição.

Dentre as características de caráter individual, deve-se considerar a importância do professor dominar o conteúdo de sua disciplina e de manter um canal aberto de comunicação e compreensão de seu aluno, conforme afirma o Professor Bernard Charlot em entrevista na mesma matéria:

Um professor que sabe muito da matéria, mas não como alcançar o aluno não produz aprendizagem. Assim como outro que considera o aluno, mas não sabe a matéria. (RODRIGUES, 2015, s.p.)

Além disso, de acordo com Coe et al. (2014, p.45) um "bom professor" também desenvolver outras ações que facilitam o aprendizado dos alunos.

Práticas específicas, como a necessidade de revisar o aprendizado anterior, fornecer modelos para os tipos de respostas que os alunos devem produzir, fornecer tempo adequado para a prática incorporar habilidades com segurança e desenvolver novas aprendizagens também são elementos de instrução de alta qualidade. (COE et al., 2014 p.45, tradução nossa)

Com base nas características apresentadas nesse item, observa-se que para se alcançar excelência como professor há de haver uma combinação entre aspectos pessoais e ambientais, dentre os quais o domínio do conteúdo, o compreender o outro e a proposição de novas estratégias didáticas visando a construção da aprendizagem, além de um ambiente propício e da troca de experiências entre pares. Os estudos apontam que a presença de tais aspectos contribuem para um ensino de qualidade.

\section{Identidade do docente de Geografia}

Inicio esse tópico com alguns questionamentos, que servem mais para nortear as argumentações do que para serem objetivamente respondidos. $\mathrm{O}$ que identifica os professores de Geografia dos demais? O que os torna um grupo coeso com caracteristicas muito próximas entre si? Quais são os aspectos que os destacam daqueles que atuam nas demais áreas do conhecimento? 
No meu entendimento, a identidade do docente de Geografia passa por 3 caracteristicas basilares: a inspiração, a diversidade e a curiosidade. Tratarei, na sequência, de descrever brevemente cada uma delas.

\section{Inspiração: os mestres que inspiram}

Quem dentre aqueles que assumiram a carreira docente não teve, na sua formação escolar, um mestre que materializasse o "professor ideal", aquele no qual se acredita, aquele que é exemplo, aquele que abre as portas para que o aluno se encante com a Ciência? Aquele que inspira, seja qual for a disciplina por meio de seu linguajar preciso, dos exemplos facilmente compreensíveis, do sentido concreto a conteúdo muitas vezes por demais abstrato. Aquele que por suas palavras e estratégias didáticas permite que tudo se conecte e ganhe sentido.

É dessa inspiração que falo quando apresento como exemplo, um entre inúmeros que poderiamos encontrar na nossa história brasileira e seus grandes nomes. Trago aqui a história de Antonio Frederico de Castro Alves, o poeta e Ruy Barbosa, o jurista, o político, o diplomata, dentre tantas outras denominações. Dois gênios, sem sombra de dúvidas, que viveram no mesmo tempo histórico, frequentaram as mesmas escolas, dividiram em certo momento a mesma república de estudantes de direito em São Paulo, brilharam individualmente e escreveram, cada um a seu modo, páginas definitivas da História do Brasil.

Foi por meio de Dourado (2018), um historiador e seu romance histórico que trouxe ao público aspectos muito significativos desses importantes personagens da nossa história, que descobri um professor que talvez tenha feito toda a diferença na vida desses meninos gênios. Meninos cuja genialidade lá estava desde sempre, mas cujo professor talvez tenha permitido, por meio de sua didática, fazê-la transbordar e traçar definitivamente seus caminhos. A década de 1850, a cidade Salvador, a escola o antigo Ginásio Baiano, na época uma referência para a formação das crianças e jovens da elite tradicional da Bahia.

O diretor do colégio, Dr. Abílio Cesar Borges, o educador liberal, editor de periódicos, abolicionista da sociedade britânica internacional, tinha recomendaçãoo do Império, experiência de gestão hospitalar e um bigode maior do que de todos a seu redor. Em plenos anos 50 daquele século, retirou a palmatória da sala de aula (sabe-se Deus como os professores passarão a educar seus alunos, 
cochichavam uns), aplicando evoluções do Método Castilho para que as crianças aprendessem "deslizando pelo conhecimento", e acrescentou matérias isoladas e concomitantes, isto é, no mesmo dia, uma cadeira após a outra (o que confundirá a mente dos estudantes, certamente, seguiam cochichos outros). Não eram poucas as disciplinas: Latim, Francês, Inglês, Gramática Portuguesa, Gramática Filosófica, Filosofia, Álgebra e Geometria, Retórica, História, Geografia, Música, Desenho, Dança, Ginástica, Física e Química, Sejam bem-vindos." (DOURADO, 2018, p. 27-28)

Ser professor e, principalmente ser aluno, no século XIX não devia ser tarefa simples. A escola tradicional, centrada na atuação monológica e autoritária do professor, pautada em longas exposições teóricas e num rigor disciplinar no qual imperavam os castigos físicos. Mas nesse ambiente por demais engessado surge o professor Abílio Cesar Bórges e suas práticas didáticas nada convencionais:

Dr. Abílio criou uma novidade: pôs um púlpito no salão para alunos declamarem e outros se reunirem para escutá-los. Deu o nome de Outeiro, como o altar para as festas de convento. Organizou o sarau de estréia no dia de seu próprio aniversário e convidou a comunidade. Os homens de casaca, alinhados, sentaram-se próximos ao palanque - 0 chamado Outeiro - para ver de perto os poetas mirins recitarem. Ruy poderia colocar em público seu Camões, mas a regra era ter apenas poemas autorais. (DOURADO, 2018, p. 29).

Nota-se nesses breves trechos transcritos do autor, muito do que eram as estratégias de ensino de Dr. Abílio, que buscava primar pelo conteúdo sim, mas de maneira ampla e holística, na qual disciplinas do núcleo rígido como Algebra, Gramática Portuguesa, Física, Química estavam par a par com História, Geografia, Artes, Dança, dentre outras. Outro fato revelador é a criação do "Outeiro", espaço fora da sala de aula, aberto à comunidade, no qual os alunos podiam desenvolver seus talentos como oradores, o que pode ter feito toda a diferença na formação do Poeta Castro Alves e do jurista Ruy Barbosa. Obviamente essas são elocubrações não comprováveis, mas que podem nos dar pistas e delinear o que pode vir a ser o diferencial de um "bom professor".

\section{Diversidade: as múltiplas Geografias}

Além da Inspiração que advém de professores únicos, que pode levar um aluno a abraçar a carreira docente independentemente da área do conhecimento, um aspecto particular da Geografia que a diferencia é a sua diversidade, para muito além da 
dicotomia entre Geografia Física e Geografia Humana. A Geografia é una e é múltipla, abarca interfaces com diferentes áreas do conhecimento, desde a matemática, como é o caso da geoestatistica e das geotecnologias; das teorias que embasam a formação social, econômica e de planejamento; aspectos metodológicos como os que aparecem nas pesquisas voltadas para o ensino; a física, a química e a geologia, como ocorre, por exemplo, nas disciplinas geomorfológicas, pedológicas e hidrológicas, um corpo complexo de disciplinas que permitem o estudo de aspectos naturais, sociais e tecnológicos.

São muitas Geografias numa única ciência. Esta aparente fragilidade, que numa análise menos cuidadosa pode levar a pensar que a Geografia abarca um conhecimento generalista que não permite aprofundamento é, no meu entendimento, o seu grande mérito. O transitar entre diferentes aspectos do homem e da natureza, de sua constituição como sociedade humana e suas intervenções no meio ambiente, permitem ao profissional que atua nessa área uma visão ampla e coesa do planeta e seus principais fenômenos, bem como das suas diferentes sociedades e culturas.

De acordo com Lopes; Pontuschka (2015):

Dessa maneira, uma característica essencial do conhecimento pedagógico geográfico é o desenvolvimento de saberes/fazeres/atividades, os quais, focados na análise do espaço geográfico, visam promover o raciocínio geográfico dos alunos. (LOPES; PONTUSCHKA, 2015, p.84)

Todo o conhecimento geográfico se dá por meio do estudo do espaço geográfico e da relação do homem com o meio ambiente. Nesse sentido, é impossível um professor de Geografia não desenvolver uma postura crítica pois, na sua formação, o tempo todo é confrontado com diferentes visões e diferentes perpectivas de compreensão do mundo. Esse é outro aspecto que considero fundamental na construção da identidade docente de Geografia.

\section{Curiosidade: a busca por respostas}

Uma terceira característica que, no meu entendimento, dá identidade ao professor de Geografia é a curiosidade, a busca pelo conhecimento, em especial dos fenômenos naturais e sociais e seus impactos sobre o planeta e sobre a vida na Terra. 
Como a realidade geográfica não é transparente, quer dizer, não é prontamente cognoscível, é necessário que o aluno disponha de instrumentos teóricos para superar, progressivamente, as aprendizagens baseadas no senso comum. (LOPES; PONTUSCHKA, 2015, p.85)

O professor de Geografia tem papel fundamental nessa compreensão científica da realidade, pois não basta a ele descrever os eventos ou diagnosticá-los, sejam eles próprios do funcionamento e das dinâmicas do planeta, sejam decorrentes da ação humana. O interesse pela Geografia vem com um não conformismo com a realidade e de como ela se coloca. Buscar as causas dos fenômenos, as suas interrelações e poder mensurar suas consequências é o desafio maior que faz com que um jovem abrace a carreira acadêmica, aprofunde seus estudos e se torne professor desta área.

Nesse sentido, o profissional que é movido pela admiração por outros que o inspiraram, que apresenta aos alunos as múltiplas faces dos fenômenos terrestres e das relações humanas, que leva o aluno ao raciocínio geográfico e à compreensão da complexidade dos eventos, suas interconexões e consequências e, naturalmente, faz despertar a curiosidade, a busca pelo conhecimento, não é outro senão professor de Geografia. Na minha perspectiva, esses aspectos são basilares para a formação de sua identidade profissional.

Ao lançarmos um olhar sobre as bases da Geografia nos deparamos com Ritter, considerado um dos pais dessa Ciência, que também no século XIX, sintetiza com precisão o objeto da Ciência Geográfica:

A Terra, considerada por si só, apenas um fragmento do Universo, do Cosmos, no uso amplo da palavra, que Humboldt tenha dado a ele em sua obra célebre. A Terra é grande palco, por assim dizer, da natureza, a casa, ou melhor, o berço, dos homens e das nações, o lugar de habitação da nossa raça. Não é apenas uma das regiões de espaços imensos, uma grande superfície, é o teatro onde todas as forças e as leis da Natureza são exibidas na sua variedade e independências. Além disso, é o domínio de todo o esforço humano, e a cena de uma revelação divina. A Terra deve ser estudada, portanto, em uma relação tríplice: o Universo, a Natureza, a História. (RITTER,1865 apud ALVES; PICOLLI NETO, 2009, p. 57)

Pela abrangência e complexidade do objeto da Geografia, conforme ilustra Ritter, fica evidente o quão importante é esta área do conhecimento para a formação escolar, cujo valor não pode ser considerado nem maior, nem menor do que das demais disciplinas. Professores preparados e comprometidos com a disseminação do saber, tratando a formação dos alunos como ação holística nos moldes do praticado a mais de 
um século pelo Dr. Abílio Borges, para o qual as disciplinas e as atividades extra-classe estão integradas e são indissociáveis, cada qual contribuindo para a formação plena do cidadão.

\section{Dificuldades da Educação Básica Pública no Brasil}

Voltando ao século XXI, convido o leitor à reflexão sobre como anda a Educação Básica Pública no Brasil. Diante da minha experiências por mais de 3 décadas formando professores de Geografia, é inquestionável a degeneração pela qual a educação pública vem sofrendo nas últimas décadas, em especial a Educação Básica, mesmo com a grande gama de possibilidades metodológicas e tecnológicas disponíveis e todo o investimento financeiro e de pessoal. Não estamos em uma situação minimamente adequada. No meu entendimento os fatores que nos levam a isso passam pelas questões elencadas (diagrama 2).

Diagrama 2- Fatores que compromentem a Educação Básica Pública.

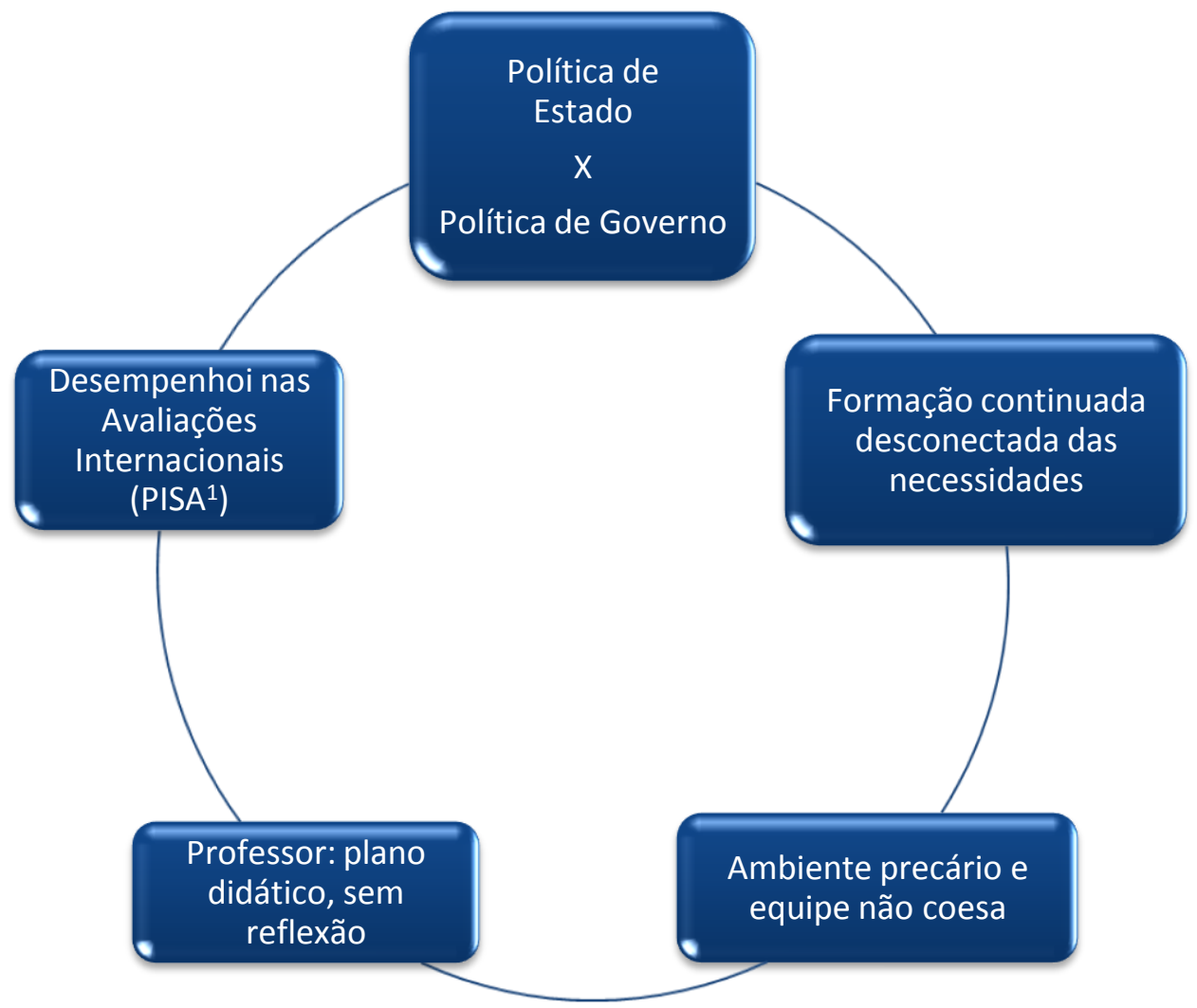

${ }^{1}$ Programme for International Student Assessment (Programa Internacional de Avaliação de AlunosFonte: Rodrigues (2015) - Organizado por: Freitas, M.I.C. (2019) 
Primeiramente considero que um problema basilar, que se reflete nos demais que serão aqui discutidos, diz respeito à Política Educacional Brasileira que deve ser, por princípio, uma Política de Estado e não uma Política de Governo, que muda a cada nova eleição. Expor a formação educacional inicial de alunos, em sua maioria das camadas sociais mais vulneráveis, às intempéries político-partidárias, é condenar parte considerável da população, nossa futura força de trabalho e de desenvolvimento, ao subemprego decorrente das sérias limitações de formação no período escolar.

Um outro fator que no meu entendimento compromete a educação básica é a formação continuada de professores, muitas vezes estruturada sem levar em conta as reais necessidades dos envolvidos, dos sistemas de ensino, das unidades escolares, bem como as carências de formação individual dos docentes. Programas de grande apelo político, usualmente elaborados para formação de grande quantidade de professores, no padrão " de cima para baixo", muitas vezes tem pouca efetividade na rotina do professor em formação.

Além disso, o ambiente precário, com baixo investimento na infra-estrutura escolar, problemas crônicos de instalações muitas vezes envelhecidas, falta de segurança para o professor atuar, principalmente em escolas periféricas, além do baixo comprometimento das equipes com o bem-estar coletivo, podem estar na base do desestímulo de professores e alunos em permanecerem na escola. Ambientes limpos, saudáveis e seguros trazem consigo o prazer da permanência e estimulam o convívio social que se coloca tão distante das escolas da atualidade, principalmente aquelas que atendem a população mais vulnerável. A consciência de que o que é público pertence e é responsabilidade de todos precisa ser resgatada dentro e fora do ambiente escolar.

Não é necessário repetir aqui o que conhecemos à exaustão sobre a rotina de um professor da rede pública, com formação muitas vezes precarizada, jornada de trabalho exaustiva e baixa remuneração. $\mathrm{O}$ acúmulo de aulas e tarefas relativas às turmas acabam por levar o docente a reproduzir conteúdos de livros didáticos ou apostilas, usualmente de conteúdo por demais simplificado, sem tempo para reflexão sobre sua prática didática.

Além disso, a resistência às mudanças decorrentes, muitas vezes da insegurança profissional levam o professor a se fechar em práticas que domine e que não demandem demasiado esforço. É o que observamos na afirmação sobre o tema, num artigo sobre a formação de professores reflexivos na área de Matemática: 
Um dos obstáculos à mudança é a insegurança pessoal do professor. Quando este trabalha com uma determinada orientação curricular já há algum tempo, domina-a e sente-se confiante para resolver qualquer problema que lhe possa surgir. É natural que o professor tenha relutância e receio em abandonar a sua base de segurança, o que mostra que a mudança não é apenas um processo cognitivo, mas envolve, também, emoções (DAY, 1999 apud SARAIVA; PONTES, 2003, p. 4-5).

Além de tais fatores, considero que as avaliações internacionais dos estudantes e das escolas, como o Programa Internacional de Avaliação de Alunos (PISA), no qual temos tido desempenho bastante inexpressivo desde sua implantação, no ano 2000, tem estimulado a criação de políticas educacionais focadas nas disciplinas que são por ele contempladas, como é o caso da Lingua Portuguesa, Matemática e Ciências, colocando numa escala diferente de prioridades as demais disciplinas, tão importante quanto essas na formação plena dos alunos da Educação Básica. Mesmo com investimento prioritário em tais disciplinas por parte do Ministério da Educação (MEC), observa-se que a melhora de desempenho dos estudantes neste programa tem ocorrido porém, de forma extremamente lenta, indicando que não encontramos o caminho para reverter o quadro crônico da baixa qualidade educacional no Brasil. A Tabela 1 ilustra o desempenho do Brasil no PISA.

Tabela 1: Desempenho do Brasil no PISA ${ }^{[1][2][3]}$

\section{Desempenho do Brasil no PISA}

\begin{tabular}{c|c|c|c|c|c|c|c}
\hline Área & 2000 & 2003 & 2006 & 2009 & 2012 & 2015 & 2018 \\
\hline $\begin{array}{c}\text { Alunos } \\
\text { Brasileiros }\end{array}$ & 4893 & 4452 & 9295 & 20127 & 18589 & 23141 & $10.691^{[2]}$ \\
\hline $\begin{array}{c}\text { Países } \\
\text { Participantes }\end{array}$ & 32 & 41 & 57 & 61 & 65 & 70 & $79^{[2]}$ \\
\hline $\begin{array}{c}\text { Colocação } \\
\text { Brasileira }\end{array}$ & $32^{\circ}$ & $40^{\circ}$ & $52^{\circ}$ & $50^{\circ}$ & $57^{\circ}$ & $63^{\circ}$ & $57^{\text {[3] }}$ \\
\hline
\end{tabular}

Fontes:

[1] OECD (Disponível em: <http://www.oecd.org/pisa/ >. Acesso em: 07/12/2019

[2] DAEB (Diretoria de Avaliação da Educação Básica) - INEP - MEC. Relatório Brasil no PISA 2018

(Versão preliminar). Brasília, INEP/MEC, 2019. 154p. Acesso em: 07/12/2019.

[3] Cerioni, C. Após dez anos Brasil melhora nos três índices de avaliação do PISA 2018. Revista Exame. São Paulo: 2019. Disponível em <https://exame.abril.com.br/brasil/apos-dez-anos-brasilmelhora-nos-tres-indices-de-avaliacao-do-pisa-2018/>. Acesso em: 07/12/2019.

Com tantas tentativas e erros no cenário educional, decorrentes de políticas voláteis e trocas constantes de diretrizes no âmbito do MEC, ditadas muitas vezes por interesses que se distanciam da formação dos alunos, observamos o fraco desempenho dos alunos em temas fundamentais para sua formação como a leitura, interpretação de 
textos, a realização de operações básicas de matemática, dentre outros, colocando nosso país em $57^{\circ}$ lugar, num total de 79 participantes do PISA 2018.

\section{As Universidades o professor de Geografia na Educação Básica}

No caso específico da Geografia, confirmando o que se passa nas demais licenciaturas, encontramos professores cuja formação inicial se dá com disciplinas fragmentadas e muitas vezes desconexas entre si. Os licenciandos, via de regra, possuem dificuldades em compreender a importância e a interrelação entre as matérias, que são tratadas em nossas universidades de forma isolada, como disciplinas individuais e não como parte de um todo geográfico. Os atuais currículos dos cursos de graduação em Geografia, muito similares nas universidades de todo o país, são compostos de disciplinas especialistas que distanciam a visão integrada que a Geografia exige, não privilegiando interfaces entre tais disciplinas, entre outras de diferentes cursos de licenciatura e nem projetos que permitam sua integração.

As aulas na Universidade, via de regra expositivas, centradas no professor, dificultam a construção dialógica do saber. Mesmo nas matérias que estimulam a sua participação ativa, os alunos universitários pouco participam e interagem com o conteúdo, tratando-o como algo que deva ser assimilado e não discutido de forma reflexiva.

Conforme o estudo de Kaercher; Tonini (2017) sobre as experiências didáticas iniciais de alunos em Estágio de Licenciatura:

Cremos que a Geografia tem algo a dizer para melhor compreendermos o mundo. Para nele nos situarmos e agirmos. Mas, e também, não crermos demasiadamente que aquilo que falamos abarque a complexidade do mundo. Daí a necessidade ao bom docente fazer perguntas abertas - aquelas que não temos as respostas de antemão - para que o aluno seja, de fato, convidado (cobrado?) a emitir sua opinião. Esse processo dialógico, juntamente com a escrita, é central em uma docência que estimule a reflexão e a ampliação da visão de mundo dos alunos. (KAERCHER; TONINI, 2017, p. 255)

As pesquisas conduzidas no ambiente universitário também tendem a ser especializadas, fortalecendo o currículo dos lideres pesquisadores e facilitando as publicações delas decorrentes, mas enfraquecendo a formação global do licenciando.

Observamos, ainda, a oferta de disciplinas e temas de pesquisa em educação muitas vezes distantes das reais necessidades da escola, com as quais os canais de 
diálogo usualmente são abertos pelos pesquisadores das universidades por meio de proposição de temas de estudo conjunto e de intervenções no ambiente escolar. É raro surgir no ambiente universitário, em especial nas licenciaturas, demandas vindas do poder público local ou das secretarias de educação municipais e estaduais, buscando soluções de questões teóricas e práticas muitas vezes elementares, que podem transformar a formação dos alunos do setor público.

Isso se deve, em parte, ao fato de que muitos sistemas educacionais possuirem suas próprias estruturas e equipes de formação continuada de professores, o que limita participações externas, como por exemplo, das universidades, sendo sempre formalmente receptivo mas, em termos práticos, não facilitando a implantação e/ou continuidade dos trabalhos propostos.

Pelo lado das universidades observa-se pouca flexibilidade nas linhas de pesquisa dos pesquisadores líderes, que justamente buscam se manter fiéis ao tema dos seus estudos, dificultando a abertura de novas frentes de pesquisa mais compatíveis com eventuais necessidades do sistema de ensino parceiro. Isso decorre da constante pressão exercida pela própria estrutura universitária e órgãos de formento, que valorizam prioritariamente a produção científica em detrimento de ações da área de ensino ou extensão decorrentes dos projetos realizados nesse âmbito.

\section{A Formação Continuada de Professores da Educação Básica}

Em termos de programas de formação continuada de professores de sistemas de ensino público, sejam eles municipal, estadual ou federal, observa-se propostas sem continuidade de uma para outra gestão, conforme já comentado nesse texto, vindas de “cima para baixo". Usualmente, tais propostas são planejadas em ambientes distantes do professor que está em sala de aula e recebidas pelo professor como obrigatórias ou como requisitos para sua progressão horizontal.

Minha experiência de formação continuada de professores que destaco neste texto refere-se ao período de 2004 a 2009, no Centro de Educação Continuada em Educação Científica, Matemática e Ambiental (CECEMCA) da UNESP, detalhado em Freitas (2011), cujo projeto compunha a Rede Nacional de Formação Continuada, coordenado pela Secretaria de Educação Básica do MEC. A Rede era formada por 19 Universidades Públicas e Comunitárias nas diferentes áreas de conhecimento, geograficamente espalhadas por grande parte do Brasil, que produzissem material 
didático original na forma de livros e guias didáticos, bem como cursos de formação continuada para os professores dos sistemas de ensino públicos participantes.

Visando realizar uma breve contextualização do projeto, as ações de formação continuada realizadas no CECEMCA/UNESP predominavam nos Campus de Rio Claro e Bauru, tinham o diferencial de levar em conta a experiência e a prática do professor, oferecendo condições para a experimentação de novos caminhos pedagógicos e, via de regra, eram muito bem aceitas pelos sistemas de ensino e pelos professores.

O CECEMCA atuou desde a Educação Infantil até os anos finais do Ensino Fundamental, realizando cursos semi-presenciais e na modalidade de Educação a Distância (EAD - Plataforma Teleduc/Unicamp), nas áreas de Matemática, Ciências, Geografia e Educação Ambiental.

No total foram formados 11984 professores, todos certificado pela UNESP, de acordo com Universidade Estadual Paulista (2010) e Freitas (2011, p. 49), em cursos oferecidos com carga horária que variava de 40 a 120h, cuja estruturada contemplava a formação de formadores (professores parceiros, alunos de pós-graduação e alunos dos anos finais da graduação da Universidade), tutores (professores locais indicados pelas redes de ensino parceiras) e os professores das redes parceiras formados pelos formadores do Centro e pelos tutores locais. Ao longo dos 5 anos em que houve a participação da UNESP na Rede Nacional de Formação Continuada foram cerca de 4,8 milhões de reais investidos pelo governo federal, numa média de aproximadamente 400 reais por professor formado nas ações.

No caso da experiência na formação continuada de professores de Geografia, especificamente na área de Cartografia e Meio Ambiente, sob minha responsabilidade, foram realizadas formações em 36 municipios de 4 Estados: Bahia, Mato Grosso do Sul, Piauí e São Paulo. Os cursos formaram 138 tutores e 1345 professores, cuja metodologia envolvia etapas contemplando o contato, planejamento e gerenciamento com as lideranças da rede de ensino parceira; a formação de grupos de estudos interdisciplinares coordenados pelos formadores do centro e pelos tutores locais, que coletavam as contribuições dos professores para a adequação de material e metodologias à realidade local.

A figura ilustra a evolução das ações de formação do CECEMCA no período de vigência do projeto na UNESP (gráfico 2). 
Gráfico 2- Evolução da Ações de Formação do CECEMCA - UNESP (2004 a 2008)

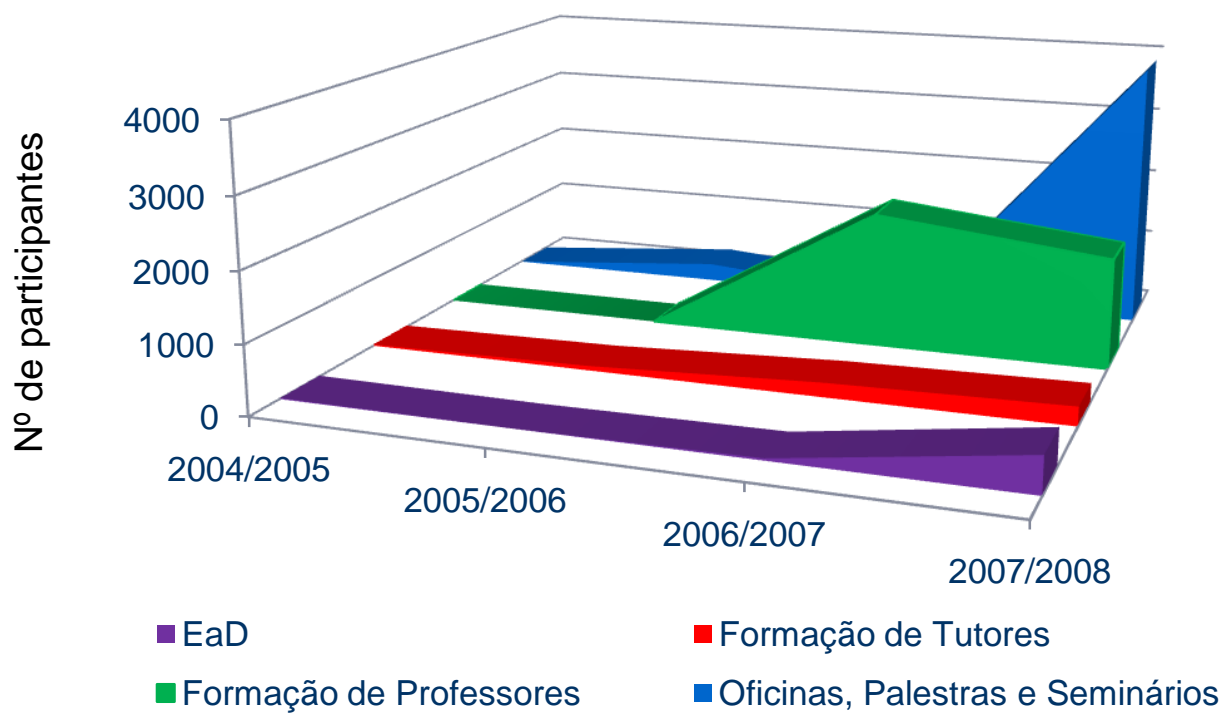

Fonte: Universidade Estadual Paulista (2010) - Organizado por: Ramos, E. (2010)

Dentre os resultados positivos dessas ações de formação continuada destaco que os cursos permitiram aos participantes a integração dos saberes entre o que vem sendo produzido na Universidade e as práticas na escola. Outro aspecto muito positivo das formações foi a possibilidade de adequação do material didático disponível às características geográficas locais, por meio da ação dos tutores e formadores. Deve-se destacar, ainda, a importância dos tutores em estimular os grupos de estudos no desenvolvimento de atividades do curso, com acompanhamento dos formadores, por meio de plataforma EaD.

No processo de elaboração desse artigo, tendo contato com entrevistas das revistas Carta Capital e revista Nova Escola, nas quais o Professor Bernard Charlot fala sobre formação de professores e o saber construído na Escola, destaco uma resposta relativa à experimentação pedagógica, que normalmente encontramos nas intervenções da Universidade no ambiente escolar. Bernard Charlot afirma com propriedade:

Existe uma máxima da educação de que toda e qualquer experimentação pedagógica dá certo. Isso ocorre porque o próprio fato de experimentar causa uma mobilização positiva, mas quando se aplica em escala, o entusiasmo não se repete tampouco o resultado. Por outro lado, os jovens precisam de indicativos de por onde ir. (RODRIGUES, 2015, s.p.)

$\mathrm{Na}$ experiência dos cursos de formação continuada do CECEMCA pude observar a mobilização positiva entre sistemas de ensino parceiros e as Universidades 
envolvidas, conforme apontou Bernard Charlot em Rodrigues (2015). Minha experiência e de outros professores que trabalharam com formação continuada apontam para a efetividade desses projetos quando de sua realização mas que, em muitos casos, não transformam a prática efetiva do professor em sala de aula, quando de volta a sua rotina de trabalho.

Na busca de respostas para esse fato, me remeto a Tardif (2002), que discorre sobre como se dá a construção dos saberes dos professores:

Os professores que encontrei e observei não colocam todos os seus saberes em pé de igualdade, mas tendem a hierarquizá-los em função de sua utilidade no ensino. [...] Nesta ótica, os saberes oriundos da experiência de trabalho cotidiana parecem constituir o alicerce da prática e da competência profissionais, pois essa experiência é, para o professor, a condição para a aquisição e produção de seus próprios saberes profissionais (TARDIF, 2002, p.21).

Ao longo de minha atuação como gestora e formadora de cursos de formação continuada de professores na disciplina Cartografia, dentro e fora do contexto do CECEMCA, constatei tal conduta dos professores que frequentaram as ações. Havia, por parte deles, uma seleção aparentemente instintiva de conteúdos que pudessem aprimorar suas práticas didáticas, que decorria de suas experiências em sala de aula. Se houvesse espaço no ambiente de formação, era com esses temas e conteúdos que os professores se prontificavam a trabalhar, desenvolver e aprofundar seus estudos, tendo todos os demais aspectos pouco ou nenhum interesse de consolidação. Nessas situações, confirmei na prática que é o "saber oriundo da experiência" que dita a hierarquia de saberes do professor, que se faz de forma particular e única, pois tem como referência a realidade de trabalho e a rotina de cada um.

Mas e o aluno? Como se dá seu aprendizado? Esta não é uma resposta nem simples, muito menos imediata. Um indicativo do caminho do aprendizado do aluno pode estar nas palavras Bernard Charlot em trecho de sua entrevista para a Revista Nova Escola:

O que faz o aluno aprender é sua própria atividade intelectual, não a do mestre. O trabalho do educador é despertar e promover essa atividade. (MARANGON e BENCINI, 2006, p. 3)

Imagino que se a mais de 30 anos, nos meus primeiros passos como professora, eu tivesse ouvido esta afirmação, posso garantir que muito mais rapidamente teria alcançado tal compreensão que a prática didática lentamente me deu. $\mathrm{O}$ professor mediador, o professor que conduz o aprendizado, a postura criativa e desafiadora de um 
Dr. Abílio Borges, juntamente com os demais aspectos aqui tratados dão o amálgama do aprendizado, nessa delicada química praticada diariamente na sala de aula por professores e alunos, a construção do saber.

\section{Considerações Finais}

Diante das divagações, ações e reflexões apresentadas nesse texto, sobre a questão da identidade docente e das práticas de formação inicial e continuada no âmbito da Geografia, coloco alguns desafios que, no meu entendimento, propiciarão um avançar qualitativo na formação e na atuação dos professores de Geografia nas escolas.

Primeiramente, deveremos pensar, na formação inicial em nossas Universidades, na integração das disciplinas de graduação em Geografia por meio de projetos didáticos temáticos. O transitar entre diferentes disciplinas pensadas de forma integrada, seja nos temas ou nas áreas de estudo, permitirão aos alunos de licenciatura a compreensão da complexidade da Geografia e, ao mesmo tempo, da sua universalidade.

Ainda no contexto acadêmico, destaco que as Universidades, por meio de departamentos e conselhos de curso, devem estimular a realização de ações pedagógicas em escolas públicas, de caráter institucional contínuo, com o planejamento conjunto de estratégias didáticas no nível local e regional, a curto, médio e longo prazos, visando atender demandas de unidades escolares de sua área de abrangência. Tais ações permitirão um aumento da eficiência escolar combinado com o aperfeiçoamento dos estudantes dos últimos anos das licenciaturas em seus períodos de estágio supervisionado.

Finalmente, considero fortemente produtivo fomentar ações de formação continuada dos professores da Educação Básica considerando a realidade docente e seu saber construído, apoiadas nas trocas com os seus pares. Tais ações podem ter como base algumas das diretrizes definidas na formação de grupos de estudos, nos moldes exemplificados no CECEMCA/UNESP, respeitando as necessidades dos docentes e das escolas. 


\section{Referências}

ALVES, F.D.; PICOLLI NETO, D. O Legado Teórico-metodológico De Karl Ritter: Contribuições para a sistematização da geografia. Geo UERJ - Ano 11, v.3, n.20, $2^{\circ}$ semestre de 2009. Rio de Janeiro: 2009. p.48-63.

COE, R.; ALOISI, C.; HIGGINS, S.; MAJOR, L.E. What makes great teaching? Rewiew of the underpinning research. Durham, Center of Evaluation and Monitoring, 2014. 57p.

FREITAS, M.I.C. A Cartografia no Ensino Básico: Experiências em cursos de formação continuada de professores. Tese de Livre Docência. IGCE/Unesp, 2011. 191p.

KAERCHER, N.A; TONINI, I.M. Artesania, felicidade, empatia: assuntos não geográficos para o estagiário de Geografia construir sua identidade docente. Revista Geographia Meridionalis. v. 03, n. 02/Out/2017. Pelotas: 2017. p. 251-273. Disponível em: < https://periodicos.ufpel.edu.br/ojs2/index.php/Geographis/article/view/11864/7785> Acesso em: 09/12/2019.

LOPES, C. S.; PONTUSCHKA, N. N. O conhecimento pedagógico do conteúdo na prática profissional de professores de geografia. GEOUSP - Espaço e Tempo. v.19, n.1, p. 076 - 092, São Paulo: 2015.

MARANGON, C.; BENCINI, R. Bernard Charlot: O conflito nasce quando o professor não ensina. Nova Escola, s.p., 01 out. 2006. São Paulo: 2006. Disponível em: < https://novaescola.org.br/conteudo/871/bernard-charlot-o-conflito-nasce-quando-oprofessor-nao-ensina>

MICHAELIS... Michaelis Dicionário Brasileiro da Língua Portuguesa. São Paulo: Ed. Melhoramentos, 2019. (on line) Disponível em: < https://michaelis.uol.com.br> Acesso em: 09/12/2019.

RODRIGUES, C. O que faz o bom professor. Carta Capital, s.p., 27 jul. 2015. São Paulo: 2015. Disponível em: <https://www.cartacapital.com.br/educacao/o-que-faz-obom-professor/>. Acesso em: 09/12/2019.

SARAIVA, M.; PONTE, J. P. O trabalho colaborativo e o desenvolvimento profissional do professor de Matemática. Quadrante, 12(2), 25-52. Lisboa: 2003. Disponível em: < https://repositorio.ul.pt/bitstream/10451/3077/1/03-SaraivaPonte\%28Quadrante\%29.pdf>. Acesso em: 09/12/2019.

STIVANIN, N.F.; ZANCHET, B.M.B.A. Programas de inserção à docência: percepções de professores universitários. Rev. Docência Ens. Sup., v.5, n.1, p.67-90. Belo Horizonte: 2015. Disponível em: < https://periodicos.ufmg.br/index.php/rdes/article/view/1972/1314> Acesso em: 09/12/2019. 
TARDIF, M. Saberes Docentes e Formação Profissional. Tradução: Francisco Pereira, 11 ed. Petrópolis: Editora Vozes Ltda, 2010. 325p.

UNIVERSIDADE ESTADUAL PAULISTA. Pró-Reitoria de Extensão Universitária. Programa do Centro de Educação Continuada em Educação Matemática,

Científica e Ambiental. Relatório de Atividades CECEMCA/UNESP: 2008 - 2009. São Paulo: PROEX, 2010. 264p. 